\title{
Omissão de nutrientes na cultura da alface (Lactuca sativa)
}

DOI: https://doi.org/10.35168/2176-896X.UTP.Tuiuti.2020.Vol6.N61.pp68-87

Caio Henrique Pol

Aluno de Agronomia da Universidade Tuiuti do Paraná. caiohenriquepol@gmail.com

Jéssica Alves Nogaroli

Doutorado em Agronomia - UEPG. Pós-doutorado em Agronomia - UEPG (2019 - atual). Professora na Universidade Tuiuti do Paraná e Coordenadora do Laboratório de Fertilidade do Solo. jessica.nogaroli@utp.br 


\section{Omissão de nutrientes na cultura da alface (Lactuca sativa)}

\section{Resumo}

As escalas de sintomas de deficiência visual desempenham um importante papel, auxiliando o produtor agrícola a identificar, no campo, as possíveis deficiências de macro e micronutrientes. Sabendo-se disso, o objetivo desse trabalho foi avaliar a omissão de macro e micronutrientes no desenvolvimento da cultura da alface (Jonction - cultivar do tipo crespa), identificando e descrevendo os sintomas visuais e morfológicos causados pela omissão de nutrientes. O delineamento experimental foi inteiramente casualizado com 11 tratamentos e 3 repetições, totalizando 33 unidades experimentais. Os tratamentos consistiram na fertirrigação das unidades experimentais com a solução completa e da solução completa com omissão de nitrogênio $(\mathrm{N})$, fósforo $(\mathrm{P})$, potássio $(\mathrm{K})$, cálcio $(\mathrm{Ca})$, magnésio $(\mathrm{Mg})$, enxofre $(\mathrm{S})$, ferro $(\mathrm{Fe})$, manganês $(\mathrm{Mn})$, zinco (Zn) e boro (B). A escala visual dos sintomas de deficiência foi realizada por meio de fotos semanais (seis semanas). Também foram avaliados: peso verde da parte aérea (PVPA) e parte radicular (PVPR); peso seco da parte aérea (PSPA) e parte radicular (PSPR) e comprimento de raiz (CR) na cultura da alface, ao final do experimento. $\mathrm{O}$ efeito supressor na cultura da alface durante a omissão dos macronutrientes na solução nutritiva foi na seguinte ordem: P, K, Ca e Mg; e para micronutrientes foi na seguinte ordem: Mn, B, Zn e Fe. A ausência de P na solução nutritiva foi a principal limitante para o desenvolvimento da cultura da alface.

Palavras-chave: Nutrição de plantas. Hortaliças folhosas. Deficiência nutricional. 


\section{Nutrients omission in lettuce (Lactuca sativa)}

\section{Abstract}

The scales of visual impairment symptoms play an important role, helping the agricultural producer to identify, in the field, possible macro and micronutrient deficiencies. Knowing this, the objective of this work was to evaluate the omission of macro and micronutrients in the development of lettuce (Jonction - curly type cultivar), identifying and describing the visual and morphological symptoms caused by the omission of nutrients. The experimental design was completely randomized with 11 treatments and 3 repetitions, totaling 33 experimental units. The treatments consisted of fertigation of the experimental units with the complete solution and the complete solution with omission of nitrogen $(\mathrm{N})$, phosphorus $(\mathrm{P})$, potassium $(\mathrm{K})$, calcium (Ca), magnesium $(\mathrm{Mg})$, sulfur $(\mathrm{S})$, iron $(\mathrm{Fe})$, manganese $(\mathrm{Mn})$, zinc $(\mathrm{Zn})$ and boron $(\mathrm{B})$. The visual scale of the symptoms of deficiency was performed using weekly photos (six weeks). Also evaluated were: green weight of the aerial part (PVA) and root part (PVPR); dry weight of aerial part (PSPA) and root part (PSPR) and root length (CR) in lettuce culture, at the end of the experiment. The suppressive effect on lettuce culture during the omission of macronutrients in the nutrient solution was in the following order: $\mathrm{P}$, $\mathrm{K}, \mathrm{Ca}$ and $\mathrm{Mg}$; and for micronutrients it was in the following order: $\mathrm{Mn}, \mathrm{B}, \mathrm{Zn}$ and Fe. The absence of $\mathrm{P}$ in the nutrient solution was the main limiting factor for the development of lettuce culture.

Keywords: Plant nutrition. Leafy vegetables. Nutritional deficiency. 


\section{Omissão de nutrientes na cultura da alface (Lactuca sativa)}

\section{Introdução}

Após muitas décadas de adaptação, as hortaliças representam uma das mais importantes fontes de alimento para o mundo, destacando sua relação com a saúde (COSTA \& SALA, 2005). Dentre as hortaliças mais consumidas temos a alface. A alface é originada do leste Mediterrâneo e utilizada na alimentação desde 500 a.C, e desde então é cultivada em todo o mundo para o consumo culinário e farmacêutico. Dentre os maiores produtores de alface no mundo, a China vem em primeiro lugar com 23,6 milhões de toneladas anuais, que representa $52 \%$ da produção mundial e em seguida se encontra os Estados Unidos com 20\% da produção mundial (MAKISHIMA \& MELO, 2005). A alface é explorada em todo território brasileiro e cultivada em diferentes sistemas de produção: em solo ou hidroponia e cultivo convencional ou orgânico (SOUZA \& RESENDE, 2006). No Brasil, são aproximadamente 108 mil unidades produtoras com alface, gerando 908.186 toneladas de alface (IBGE, 2017). São cultivados em 842 mil hectares em hortaliças no brasil, sendo que 87 mil hectares são de alface, gerando na agricultura familiar 5 empregos diretos por hectare (ABCSEM, 2014).

As condições climáticas das principais regiões produtoras de hortaliças no Brasil possuem grandes variações, o que acarreta prejuízos, perdas de produtividade e qualidade, se fazendo necessário, muitas das vezes, o seu cultivo em túneis cobertos, produção em telados, estufas e sistemas hidropônicos, a fim de diminuir estes impactos negativos. O crescimento e a produtividade da alface dependem do clima, variedade, água, fertilizantes e da concentração de macro e micronutrientes na sua estrutura (KIRKBY \& ROMHELD, 2007). Os elementos apontados como macronutrientes são: nitrogênio $(\mathrm{N})$, fósforo $(\mathrm{P})$, potássio $(\mathrm{K})$, cálcio $(\mathrm{Ca})$, magnésio $(\mathrm{Mg})$ e enxofre $(\mathrm{S})$. Já os elementos encontrados em menores concentrações são os micronutrientes, sendo eles, ferro (Fe), manganês (Mn), zinco (Zn), boro (B), e entre outros (MALAVOLTA, 2006). 


\section{Omissão de nutrientes na cultura da alface (Lactuca sativa)}

Nas plantas, o $\mathrm{N}$ é o componente de proteínas, ácidos nucleicos e outras estruturas celulares, já o S compõe alguns aminoácidos e é importante para a qualidade do produto final, como grãos e matéria seca (MARSCHNER, 2012). O S também é exigido para a formação de aminoácidos, proteínas e para a resistência ao frio (MALAVOLTA, 2006). O P promove a formação inicial, desenvolvimento da raiz e o crescimento da planta (TISCHER \& NETO, 2012). O P também faz parte dos ácidos nucléicos e é importante na transferência de energia e carboidrato nas células foliares (Marschner, 2012). A função do K basicamente é regular processos essenciais como uso eficiente de água, formação de amido e síntese proteica e é essencial na osmorregulação, extensão celular e movimento estomático (MARSCHNER, 2012). O Ca contribui no fortalecimento de todos os órgãos das plantas, principalmente raízes e folhas (MALAVOLTA, 2006). O Ca na planta pode favorecer a estrutura da parede celular; redução da morte de botões apicais; aumentar a eficiência dos nódulos em leguminosas; e manutenção do sistema radicular (MARSCHNER, 2012). O Mg é o elemento responsável pela fotossíntese e coloração verde das plantas, também chamado de clorofila. (Borges, 2006). Também é importante para a eficiência da fotossíntese (Marschner, 2012). A importância do B para a planta é que o elemento se torna essencial para o crescimento das células, principalmente, nas regiões mais novas da planta (MALAVOLTA, 2006). O Fe age como catalisador na formação da clorofila e como carregador de oxigênio (BORGES, 2006). No caso do Mn, sua importância é encontrada na fotossíntese e síntese de clorofila (FAQUIN, 2002). Por fim, o Zn que é responsável pela ativação enzimática na planta e controla importantes reguladores de crescimento (UNIFERTIL, 2012). Nas plantas, esses micronutrientes são componentes de algumas proteínas e fito-hormônios, integridade da membrana e ativadores de várias enzimas (MARSCHNER, 2012).

O diagnóstico visual é utilizado para entender qual o nutriente ausente no desenvolvimento da planta, observando sintomas (Faquin, 2002). Consiste em avaliar e comparar a aparência de uma planta que recebeu uma solução com todos os nutrientes necessários, com outra planta que recebeu 


\section{Omissão de nutrientes na cultura da alface (Lactuca sativa)}

uma solução com deficiência de um ou mais nutrientes (PETRAZZINI et al, 2011). Na maioria dos casos os sintomas nas folhas são os primeiros a serem observados, pois é aquele que melhor reflete o estado nutricional da planta (MALAVOLTA, 2006). No entanto, antes da manifestação visível da deficiência de nutrientes, o crescimento ou a produção da planta pode já estar afetada por essa deficiência (Faquin, 2002). Para a diagnose visual estabelecer os sintomas das plantas, é importante o conhecimento da cultura e o desenvolvimento de experimentos, os quais vão ajudar a simular os desequilíbrios nutricionais. O sintoma de deficiência visual pode ser complicado no caso de plantas submetidas a mais de um nutriente mineral em níveis inadequados ou quando a deficiência desse nutriente ocorre simultaneamente com a toxidez de outro (Petrazzini et al, 2011). Entretanto, poucos estudos são encontrados sobre omissão de nutrientes em alface bem como escalas que auxiliem o produtor a identificar, no campo, os possíveis sintomas visuais ocasionados pela deficiência nutricional.

Portanto, o objetivo do trabalho foi avaliar a omissão de macro (N, P, K, Ca, Mg e S) e micronutrientes (Fe, Mn, Zn e B) no desenvolvimento da cultura da alface (Jonction - cultivar do tipo crespa), identificando e descrevendo os sintomas visuais e morfológicos causados pela omissão de nutrientes.

\section{Fundamentação teórica - Desenvolvimento}

\subsection{Material e métodos}

O experimento começou a ser realizado na casa de vegetação (Casa 1) da Universidade Tuiuti do Paraná, Curitiba, Paraná, Brasil. Entretanto, foi transferido para a Fazenda Agropol em Arapoti, Paraná, Brasil, devido as circunstâncias do Covid-19. O experimento teve início em Março/2020 


\section{Omissão de nutrientes na cultura da alface (Lactuca sativa)}

e permaneceu até junho/2020. O delineamento experimental foi inteiramente casualizado (DIC) com 11 tratamentos e 3 repetições, totalizando 33 unidades experimentais. Os tratamentos estão descritos na Tabela 1.

O experimento foi conduzido em baldes de 3,6 dm 3 (unidades experimentais), com uma torneira ao fundo do balde para que o excesso de solução nutritiva pudesse ser drenado. Os baldes foram preenchidos com areia, a qual foi lavada com ácido clorídrico $(\mathrm{HCl}) 3 \%$, peneirada e posteriormente enxaguada com água deionizada (de osmose reversa).

A solução nutritiva completa (T1) foi realizada conforme sugestão de Hoagland \& Arnon (1950) e as demais soluções nutritivas (T2 ao T11) foram omitidos os nutrientes da solução completa. Todas as soluções foram preparadas com reagentes PA e água deionizada (de osmose reversa) e durante todo o experimento foi controlado os valores de $\mathrm{pH}(6,0$ a 7,0$)$ e condutividade elétrica $(\sim$ 2,5 dS m-1) das soluções nutritivas.

A alface utilizada no experimento foi do tipo crespa, cultivar Jonction - Rijk Zwaan. Essa cultivar apresenta as seguintes características: folhas extremamente grossas, o que a torna muito resistente a altas temperaturas; excelente tolerância à queima de borda e ao pendoamento precoce; resistência ao fungo Pythium; resistência genética a diversas raças de Míldio; ciclo de até 35 dias após transplantio, dependendo do clima e do manejo do produtor; potencial de 350 g por cabeça e população de plantio recomendada de até 16 plantas por $\mathrm{m}^{2}$. (ZWAAN, 2020).

A semeadura da alface foi realizada em 06/04/2020, com 3 (três) sementes em cada unidade experimental. Após germinação, foi realizado o raleio das plântulas deixando somente uma planta por unidade experimental. Durante as 2 primeiras semanas após semeadura, as unidades experimentais foram irrigadas com água deionizada e/ou solução nutritiva diluída. A solução nutritiva diluída apresentava todos os macros e micronutrientes porem em menores proporções, isso 


\section{Omissão de nutrientes na cultura da alface (Lactuca sativa)}

foi feito para melhorar a germinação e crescimento inicial da planta. Na solução diluída continha: fosfato monopotássico (KH2PO4), nitrato de potássio (KNO3), sulfato de cobre pentahidratado $(\mathrm{Ca}(\mathrm{NO} 3) 25 \mathrm{H} 2 \mathrm{O})$, sulfato de magnésio $(\mathrm{MgSO} 4.7 \mathrm{H} 2 \mathrm{O})$, solução de micronutrientes (ácido bórico (H3BO3), cloreto de manganês ( $\mathrm{MnCl} 2.4 \mathrm{H} 2 \mathrm{O})$, cloreto de zinco $(\mathrm{ZnCl} 2)$, cloreto de cobre $(\mathrm{CuCl} 2)$ e ácido molibdico (H2MoO4H2O)) e solução Fe EDTA. As unidades experimentais foram supridas com 50-100 ml das soluções nutritivas, sendo que nas primeiras 3 semanas foram $100 \mathrm{ml}$ utilizado e nas últimas 3 semanas de tratamento $50 \mathrm{ml}$, isso porque a areia se encontrava muito encharcada.

A escala visual dos sintomas de deficiência foi realizada por meio de fotos semanais, iniciando a partir da aplicação da solução nutritiva, 2 (duas) semanas após a semeadura. Também foram avaliados: (i) peso verde da parte aérea (PVPA); (ii) peso verde da parte radicular (PVPR); (iii) peso seco da parte aérea (PSPA); (iv) peso seco da parte radicular (PSPR) e (v) comprimento de raiz (CR) na cultura da alface, ao final do experimento (aos 83 dias após semeadura). Para isso, foi retirada as plantas de alface das unidades experimentais, lavando as partes (parte aérea e parte radicular) em água deionizada, armazenando em sacos de papel, secando em estufa de circulação forçada de ar a $65^{\circ} \mathrm{C}$, por 24 horas e pesando em balança de precisão. O comprimento de raiz foi realizado com a raiz verde e utilizando uma régua do tipo escalímetro.

Os dados foram submetidos a análise de variância e comparação de médias, conforme delineamento experimental adotado, usando o teste de Tukey a $5 \%$ de probabilidade, executado no programa de computador SAS (SAS, 2004). A análise de variância pode ser observada na Tabela 2. O tratamento controle do experimento foi o tratamento com solução nutritiva completa (T1) por isso os demais tratamentos serão comparados ao T1. 


\section{Omissão de nutrientes na cultura da alface (Lactuca sativa)}

\subsection{Resultados e discussões}

$\mathrm{Na}$ omissão de nitrogênio $(\mathrm{N})$ na solução nutritiva T2 foi observado pequena redução no crescimento da alface da primeira a última semana de tratamento, quando comparado ao T1 (Figura 1). Também, não foi possível identificar demais deficiências na omissão de $\mathrm{N}$, como coloração amarelada nas folhas mais velhas, principal característica da ausência de $\mathrm{N}$ nas plantas. $\mathrm{O} \mathrm{N}$, em geral, é o nutriente mais requerido pelos vegetais e o mais limitante em relação ao crescimento (SOUZA et al., 2015). A carência de $\mathrm{N}$ também diminui o teor de clorofila na planta (MALAVOLTA et al., 1997). Porém na alface não apresentou as deficiências citadas anteriormente.

$\mathrm{Na}$ omissão de fósforo (P) na solução nutritiva T3 foi observado o crescimento raquítico da alface, sendo o nutriente omitido que mais prejudicou o desenvolvimento da alface, quando comparado ao T1 (Figura 1). Também foi possível observar o escurecimento das folhas de alface, isso pelo fato do processo de acúmulo de antocianina (MARSCHNER, 2012). O P desempenha um papel fundamental na fotossíntese, no metabolismo de açúcares, no armazenamento e transferência de energia, na divisão e crescimento celular e o desenvolvimento inicial das raízes (MALAVOLTA, 2006).

Na omissão de potássio $(\mathrm{K})$ na solução nutritiva T4 foi observado menor crescimento da alface quando comparado ao T1 (Figura 2). Foi observado desenvolvimento atípico das folhas, com o pecíolo mais fino e comprido, leve amarelecimento e pouca emissão foliar. O K desempenha um papel importante na regulação do potencial osmótico das células vegetais e também ativa enzimas envolvidas na respiração e fotossíntese (TAIZ \& ZEIGER, 2009).

$\mathrm{Na}$ omissão de cálcio $(\mathrm{Ca})$ na solução nutritiva T5 a alface manifestou crescimento reduzido ao decorrer do experimento (Figura 2). Na quinta e sexta semana de avaliações fotográficas, foi possível identificar o crescimento atípico das folhas com o pecíolo mais fino e o limbo foliar pouco desenvolvido no ápice da folha. Também foi possível notar o início da requeima das bordas na 


\section{Omissão de nutrientes na cultura da alface (Lactuca sativa)}

quinta semana, também conhecido por "tipburn". O Ca apresenta influência no crescimento e desenvolvimento das plantas, pois se encontra envolvido em processo como formação da parede celular, fotossíntese, divisão celular, movimentos citoplasmáticos e aumento do volume celular (MALAVOLTA et al., 1997).

$\mathrm{Na}$ omissão de magnésio $(\mathrm{Mg})$ na solução nutritiva T6 o principal sintoma da deficiência na alface foi o desenvolvimento inferior ao T1 (Figura 2). Na sexta semana de tratamento foi possível observar que as folhas ficaram sem estrutura, acarretando ao tombamento de algumas folhas mais velhas. O Mg participa de uma série de processos vitais da planta que fornecem energia como a fotossíntese, respiração, síntese de macromoléculas - carboidratos, lipídeos, proteínas - e absorção iônica (FAQUIN, 2002).

$\mathrm{Na}$ omissão de enxofre (S) na solução nutritiva T7, a alface se desenvolveu muito semelhante ao T1, não apresentando nenhum problema no desenvolvimento e nenhum tipo de sintoma foliar (Figura 3). É possível que a quantidade de S adicionado na solução nutritiva diluída utilizada no início do tratamento, teria sido o suficiente para que a planta não necessitasse mais do $\mathrm{S}$ posteriormente, assim não apresentando sintomas de deficiências. O S não apresenta o consumo excessivo de nutrientes, isso significa que o nutriente não tem o consumo de luxo (MALAVOLTA, 2006).

$\mathrm{Na}$ omissão de ferro (Fe) na solução nutritiva T8 o principal sintoma da alface foi o desenvolvimento atípico como, crescimento do pecíolo das folhas mais fino e comprido, limbo foliar pouco desenvolvido e coloração verde claro (Figura 3). As folhas apresentaram essa coloração devido ao fato de que o Fe é necessário para a síntese de alguns complexos de clorofila-proteína no cloroplasto (TAIZ \& ZEIGER, 2009).

$\mathrm{Na}$ omissão de manganês $(\mathrm{Mn})$ na solução nutritiva T9 as plantas de alface apresentaram baixo desenvolvimento até a quarta semana e posteriormente um leve crescimento até o final do 


\section{Omissão de nutrientes na cultura da alface (Lactuca sativa)}

tratamento (Figura 3). Na sexta semana foi possível observar necrose na ponta de uma das folhas mais novas. O Mn tem função principalmente como componente dos sistemas enzimáticos das plantas (MARCHNER, 2012).

$\mathrm{Na}$ omissão de zinco ( $\mathrm{Zn}$ ) na solução nutritiva T10 foi observado na alface, necrose nas folhas mais novas (Figura 4). Também teve um desenvolvimento médio em relação ao T1. O Zn tem papel fundamental em numerosos sistemas enzimáticos vegetais (PRADO, 2008). Controla a síntese de importantes reguladores de crescimento que influenciam desenvolvimento das plantas (MALAVOLTA, 2006).

$\mathrm{Na}$ omissão de boro (B) na solução nutritiva T11 a alface apresentou pouco desenvolvimento comparado ao T1, chegando ao final do tratamento com um tamanho raquítico (Figura 4). A alface demonstrou na terceira e quarta semana folhas arroxeadas. $\mathrm{Na}$ sexta semana de tratamento não apresentava mais arroxeamento, mas sim uma coloração de verde claro. O B participa no transporte de carboidratos e na formação da parede celular (FAQUIN, 2002). Assim, sua deficiência resulta em parede celular desestruturada, menos lignificada e no comprometimento da integridade da membrana celular (MALAVOLTA, 2006).

A solução nutritiva completa (T1) obteve a maior média para peso verde da parte aérea (PVPA), porém não diferiu do T7 (Tabela 3). A solução nutritiva T2 obteve médias semelhantes estatisticamente ao T4, T5, T6, T9 e T11. A alface submetida à solução T8 e T10 foram semelhantes. O T3 foi o qual obteve a menor média de PVPA. A alface T3 foi 98,83\% menor do que o T1. Na solução T1 as plantas de alface tiveram todos os nutrientes disponíveis, por isso obteve a maior média. No entanto a ausência de P na solução nutritiva foi a que mais acarretou a redução de desenvolvimento da cultura da alface. O P está ligado no processo de transferência e armazenamento de energia, afetando processos metabólicos como a síntese de proteínas e ácido nucléico (MALAVOLTA, 2006). 


\section{Omissão de nutrientes na cultura da alface (Lactuca sativa)}

A solução nutritiva T7 obteve a maior média para peso verde da parte radicular (PVPR), porém não diferiu da solução T1 e das soluções T4, T5, T6, T8, T9, T10 e T11 (Tabela 3). A solução nutritiva T2 obteve média semelhante estatisticamente com o T3. Foram também os dois tratamentos que obtiveram as menores médias de PVPR, sendo o T3 chegando a ser 94,16\% menor que a solução T7. A solução nutritiva T7 apresentou uma média superior a solução T1, chegando a 61,08\% maior que a solução nutritiva completa (T1). Malavolta et al. (1997) consideram o enxofre fundamental para as plantas, pois é constituinte dos aminoácidos cistina, metionina e cisteína, presente também em proteínas, sulfolipídeos, coenzimas e também age como ativador enzimático. Nos dados do peso seco da parte aérea (PSPA), a solução T7 foi a qual apresentou a maior média entre os dados apresentados, no entanto não diferiram estatisticamente do T1 e das soluções T4, T5, T6, T8, T9, T10 e T11 (Tabela 3). Como citado anteriormente o T7 foi o qual apresentou a melhor média entre os tratamentos, chegando a 52.88\% maior que o T1. As médias do peso seco parte radicular (PSPR) não apresentaram diferença estatisticamente, sendo assim não ouve diferença entre os tratamentos (Tabela 3). Isso ocorreu pelo fato dos valores de (PSPR) terem sido muito próximo uns aos outros. O T7 obteve a maior média para comprimento de raiz (CR), chegando a ser 21,34\% maior do que o T1 (Tabela 3). A solução nutritiva T7, não diferiu com o T1 e com os tratamentos T2, T5, T8, T9, T10, T11. A alface submetida a solução nutritiva T4 e T6 obtiveram médias semelhantes. O T3 foi novamente o tratamento que obteve a menor média nos valores de CR.

De acordo com os dados apresentados no trabalho foi possível analisar que o nutriente que mais prejudica o desenvolvimento da alface é o P, posteriormente o $\mathrm{K}$ e em seguida o Ca e $\mathrm{Mg}$ (Figuras 1 a 4 e Tabela 3). Tais informações auxiliam o manejo de nutrientes na cultura da alface, indicando que o nutriente fundamental para a produtividade é o P. Entre todos os tratamentos, a solução nutritiva sem $\mathrm{P}$ foi a que mais se destacou negativamente, as plantas apresentaram porte 


\section{Omissão de nutrientes na cultura da alface (Lactuca sativa)}

raquítico, devido ao fato do $\mathrm{P}$ estar associado à função estrutural e ao processo de transferência e de armazenamento de energia, afetando, com isso, todos os processos metabólicos, como a síntese proteica e a de ácidos nucleicos (MENGEL \& KIRKBY,1987).

Os dois macronutrientes, que conforme as médias apresentadas e os sintomas visuais, não causaram demais danos à alface foram o S e o N. Isso indica que a ausência de $\mathrm{N}$ e S, neste trabalho não ocasionou problemas. Dentre os micronutrientes, que mais afetou negativamente a alface, foi o Mn, seguido pelo B, depois o Zn e por último o Fe. Tais informações auxiliam o manejo de micronutrientes na cultura da alface, indicando que o Mn é fundamental para a produtividade e não deve ser esquecido no plano de adubação do sistema de produção.

Tabela 1. Tratamentos do experimento de omissão de macronutrientes (nitrogênio - N: fosforo - P: potássio - $\mathrm{K}$ : cálcio - Ca: magnésio - Mg e enxofre - S) e de micronutrientes (ferro - Fe: Manganês - Mn: zinco- $\mathrm{Zn}$ : boro-B) durante o cultivo de alface.

\begin{tabular}{ccccccccccccccc}
\hline & \multicolumn{10}{c}{ Omissão de macro e micronutrientes } \\
\hline Tratamento & T1 & T2 & T3 & T4 & T5 & T6 & T7 & T8 & T9 & T10 & T11 \\
\hline Solução nutritiva & Completa & $-\mathrm{N}$ & $-\mathrm{P}$ & $-\mathrm{K}$ & $-\mathrm{Ca}$ & $-\mathrm{Mg}$ & $-\mathrm{S}$ & $-\mathrm{Fe}$ & $-\mathrm{Mn}$ & $-\mathrm{Zn}$ & $-\mathrm{B}$ & & &
\end{tabular}

Tabela 2. Analise de variância do experimento de omissão de macronutrientes (nitrogênio $-\mathrm{N}$; fosforo $-\mathrm{P}$; potássio $-\mathrm{K}$; cálcio $-\mathrm{Ca}$; magnésio $-\mathrm{Mg}$ e enxofre $-\mathrm{S}$ ) e de micronutrientes (ferro - Fe; Manganês - Mn; zinco - Zn; boro - B) durante o cultivo de alface. As variáveis analisadas foram peso verde da parte aérea (PVPA); peso verde da parte radicular (PVPR); peso seco da parte aérea (PSPA); peso seco da parte radicular (PSPR) e comprimento de raiz (CR), ao final do experimento (aos 83 dias após semeadura).

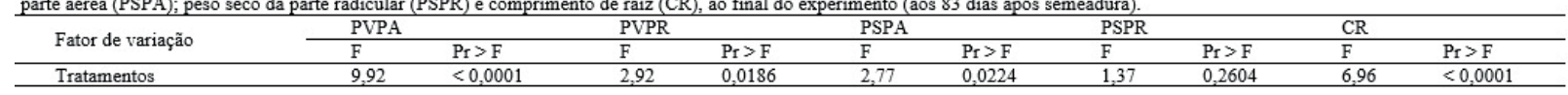

Tabela 3. Peso verde da parte aérea (PVPA); peso verde da parte radicular (PVPR); peso seco da parte aérea (PSPA); peso seco da parte radicular (PSPR) e comprimento de raiz (CR) de alface (Jonction) cultivada em solução nutritiva completa e com omissão de macronutrientes (nitrogênio - N; fosforo - $\mathrm{P}$; potássio $-\mathrm{K}$; cálcio - Ca; magnésio - $\mathrm{Mg}$ e enxofre - $\mathrm{S}$ ) e de micronutrientes (ferro $-\mathrm{Fe}$; Manganês $-\mathrm{Mn}$; zinco $-\mathrm{Zn}$; boro $-\mathrm{B}$ ).

\begin{tabular}{|c|c|c|c|c|c|c|c|c|c|c|c|}
\hline \multirow{2}{*}{ Variáveis } & \multicolumn{11}{|c|}{ Solução Nutritiva sem e com omissão de nutrientes } \\
\hline & Completa (T1) & $-\mathrm{N}(\mathrm{T} 2)$ & $-\mathrm{P}(\mathrm{T} 3)$ & $-\mathrm{K}(\mathrm{T} 4)$ & $-\mathrm{Ca}(\mathrm{T} 5)$ & $-\mathrm{Mg}(\mathrm{T} 6)$ & $-\mathrm{S}(\mathrm{T} 7)$ & $-\mathrm{Fe}(\mathrm{T} 8)$ & $-\mathrm{Mn}(\mathrm{T} 9)$ & $-\mathrm{Zn}(\mathrm{T} 10)$ & $-\mathrm{B}(\mathrm{T} 11)$ \\
\hline PVPA (g) & $17,04 \mathrm{~A}$ & $6,46 \mathrm{BC}$ & $0,20 \mathrm{C}$ & $5,75 \mathrm{BC}$ & $6,15 \mathrm{BC}$ & $5,56 \mathrm{BC}$ & $11,01 \mathrm{AB}$ & $9,02 \mathrm{~B}$ & $4,97 \mathrm{BC}$ & $7,97 \mathrm{~B}$ & $5,56 \mathrm{BC}$ \\
\hline PVPR $(g)$ & $1,00 \mathrm{AB}$ & $0,68 \mathrm{~B}$ & $0,15 \mathrm{~B}$ & $0,93 \mathrm{AB}$ & $0,98 \mathrm{AB}$ & $0,96 \mathrm{AB}$ & $2,57 \mathrm{~A}$ & $1,61 \mathrm{AB}$ & $1,40 \mathrm{AB}$ & $1,40 \mathrm{AB}$ & $1,56 \mathrm{AB}$ \\
\hline PSPA (g) & $0,49 \mathrm{AB}$ & $0,27 \mathrm{~B}$ & $0,02 \mathrm{~B}$ & $0,37 \mathrm{AB}$ & $0,31 \mathrm{AB}$ & $0,30 \mathrm{AB}$ & $1,04 \mathrm{~A}$ & $0,40 \mathrm{AB}$ & $0,40 \mathrm{AB}$ & $0,43 \mathrm{AB}$ & $0,44 \mathrm{AB}$ \\
\hline PSPR (g) & $0,08 \mathrm{~A}$ & $0,05 \mathrm{~A}$ & $0,00 \mathrm{~A}$ & $0,07 \mathrm{~A}$ & $0,06 \mathrm{~A}$ & $0,09 \mathrm{~A}$ & $0,14 \mathrm{~A}$ & $0,06 \mathrm{~A}$ & $0,07 \mathrm{~A}$ & $0,07 \mathrm{~A}$ & $0,13 \mathrm{~A}$ \\
\hline $\mathrm{CR}(\mathrm{cm})$ & $6,45 \mathrm{ABC}$ & $7,83 \mathrm{~A}$ & $4,40 \mathrm{C}$ & $5,33 \mathrm{BC}$ & $6,67 \mathrm{AB}$ & $5,37 \mathrm{BC}$ & $8,20 \mathrm{~A}$ & $7,00 \mathrm{AB}$ & $7,35 \mathrm{AB}$ & $6,97 \mathrm{AB}$ & $6,97 \mathrm{AB}$ \\
\hline
\end{tabular}

Médias de 3 repetições por tratamento (são 11 tratamentos). Médias seguidas por letras iguais maiúsculas não diferem estatisticamente pelo teste de Tukey ( $\alpha=0,05$ ), na linha. 


\section{Omissão de nutrientes na cultura da alface (Lactuca sativa)}

Figura 1. Escala de sintomas visual na alface (Jonction) durante 6 semanas de cultivo com soluções nutritivas (Hoagland \& Arnon - 1950) completa e com omissão de nitrogênio (N) e fósforo (P).

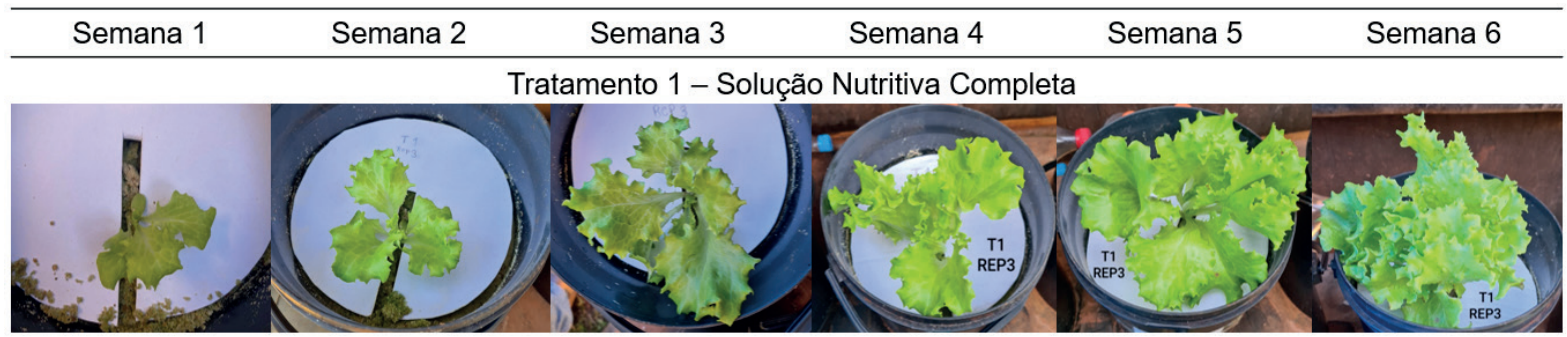

Tratamento 2 - Solução Nutritiva sem Nitrogênio (N)

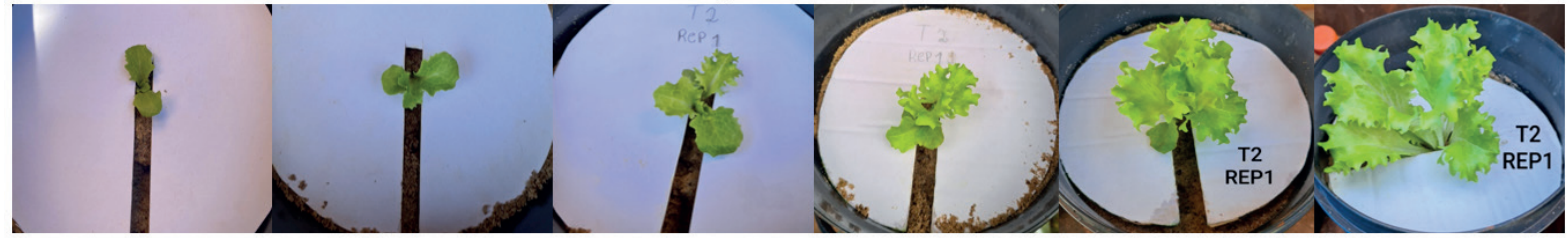

Tratamento 3 - Solução Nutritiva sem Fósforo (P)

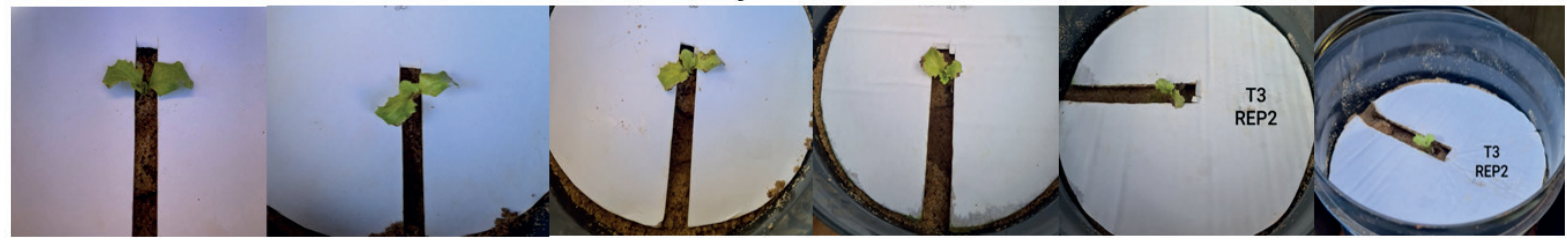




\section{Omissão de nutrientes na cultura da alface (Lactuca sativa)}

Figura 2. Escala de sintomas visual na alface (Jonction) durante 6 semanas de cultivo com soluções nutritivas (Hoagland \& Arnon - 1950) com omissão de potássio (K), cálcio (Ca) e magnésio (Mg).

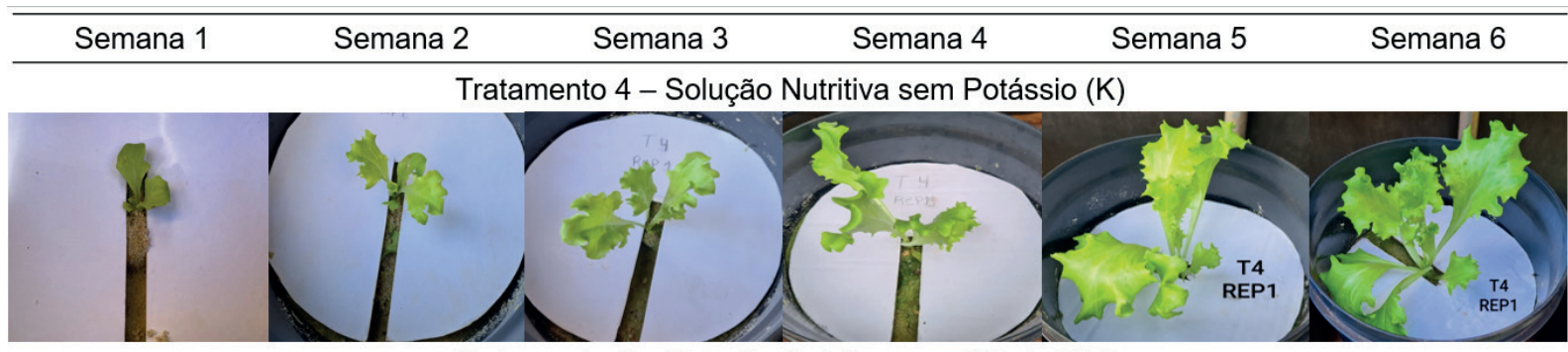

Tratamento 5 - Solução Nutritiva sem Cálcio (Ca)

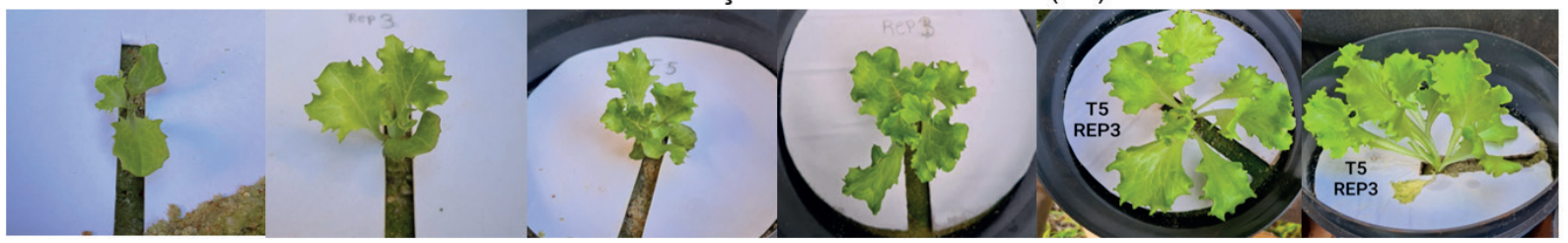

Tratamento 6 - Solução Nutritiva sem Magnésio (Mg)

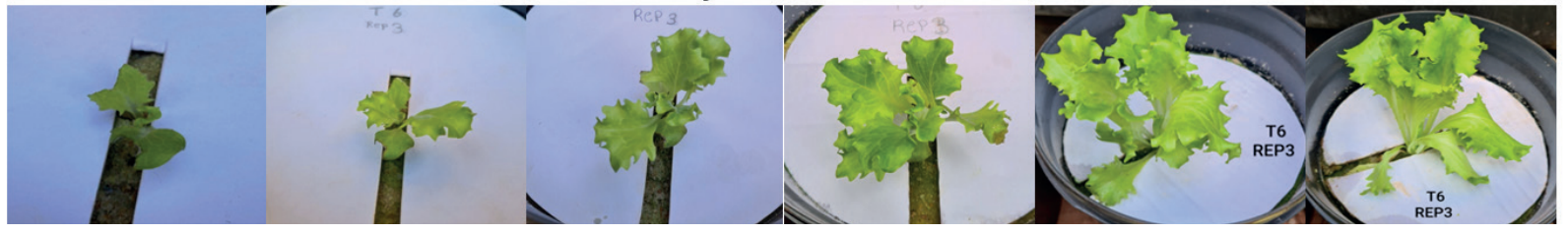




\section{Omissão de nutrientes na cultura da alface (Lactuca sativa)}

Figura 3. Escala de sintomas visual na alface (Jonction) durante 6 semanas de cultivo com soluções nutritivas (Hoagland \& Arnon - 1950) com omissão de enxofre (S), ferro (Fe) e manganês (Mn).

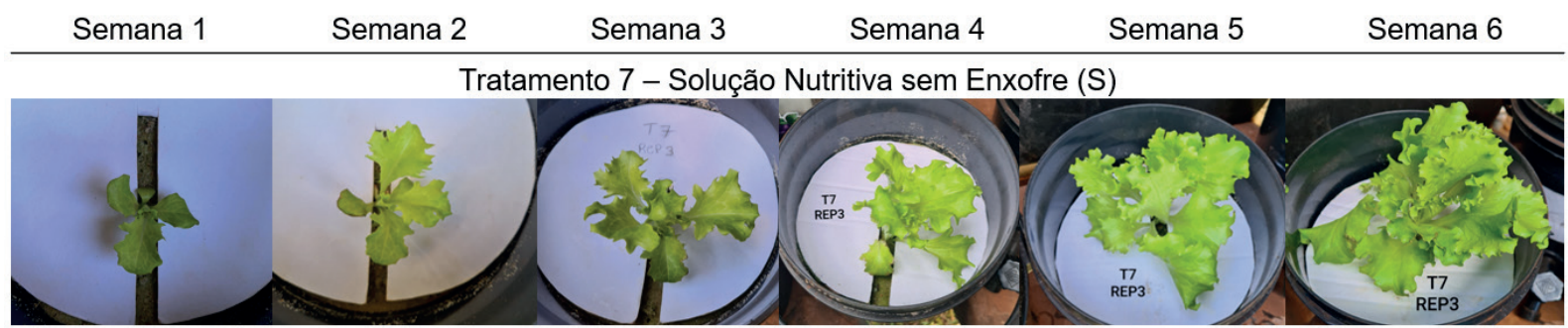

Tratamento 8 - Solução Nutritiva sem Ferro $(\mathrm{Fe})$

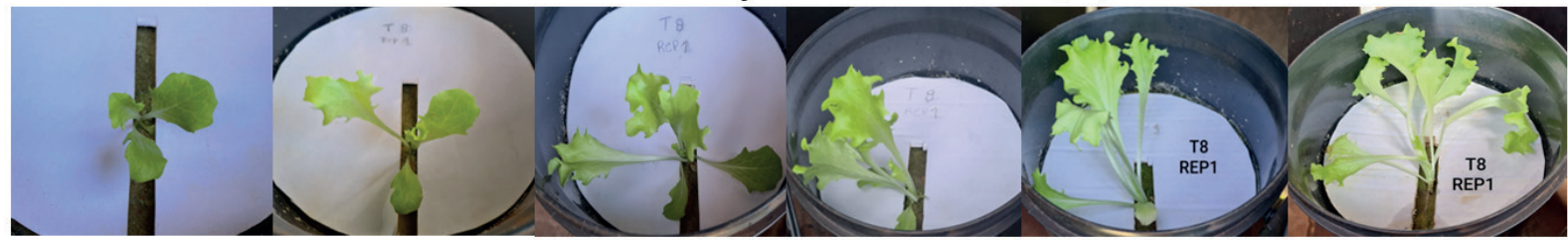

Tratamento 9 - Solução Nutritiva sem Manganês (Mn)

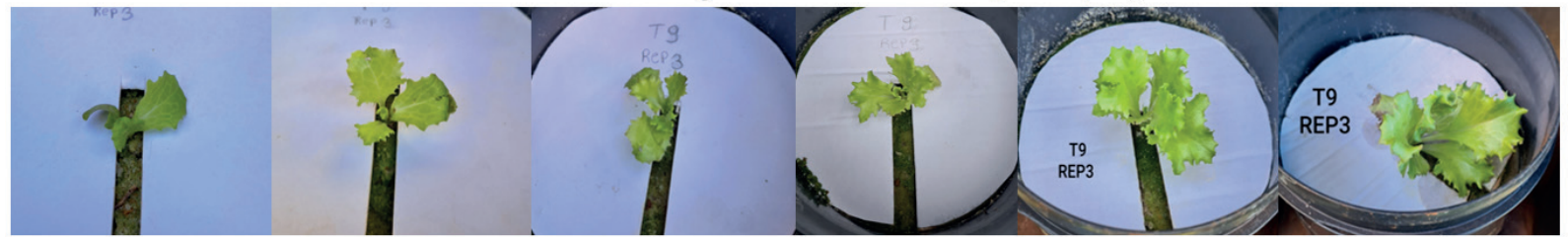




\section{Omissão de nutrientes na cultura da alface (Lactuca sativa)}

Figura 4. Escala de sintomas visual na alface (Jonction) durante 6 semanas de cultivo com soluções nutritivas (Hoagland \& Arnon - 1950) com omissão de zinco (Zn) e boro (B).

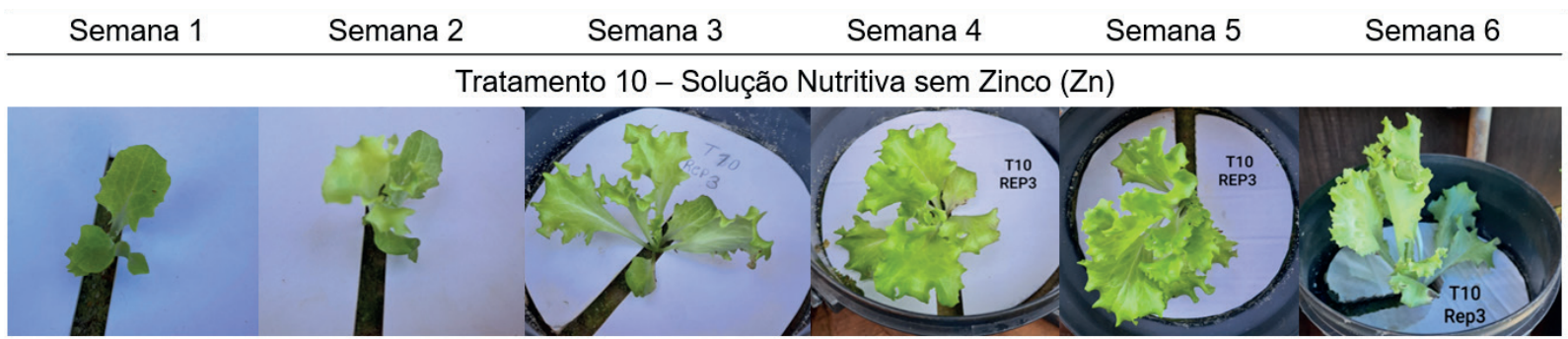

Tratamento 11 - Solução Nutritiva sem Boro (B)

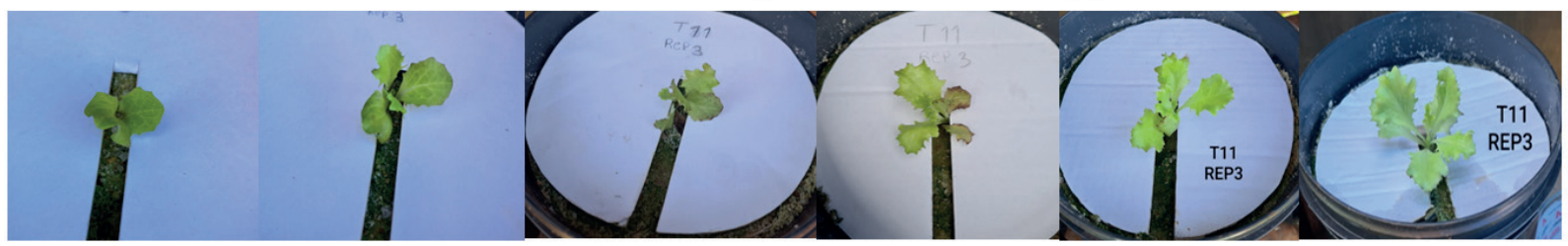

\section{Considerações finais}

O efeito supressor da omissão dos macronutrientes na solução nutritiva, reduzindo o desenvolvimento e o crescimento vegetativo da cultura da alface, foi na seguinte ordem: fosforo, potássio, cálcio e magnésio. A ausência de fósforo, na solução nutritiva e/ou na adubação de sistemas de produção, ocasiona maior dano a cultura da alface. $\mathrm{O}$ efeito supressor da omissão dos micronutrientes na solução nutritiva, reduzindo o desenvolvimento e o crescimento vegetativo da cultura da alface, foi na seguinte ordem: manganês, boro, zinco e ferro. A ausência de manganês, na solução nutritiva e/ou na adubação de sistemas de produção, ocasiona maior dano a cultura 


\section{Omissão de nutrientes na cultura da alface (Lactuca sativa)}

da alface. A ausência de nitrogênio e enxofre, na solução nutritiva e/ou na adubação de sistemas de produção, não afetaram a cultura da alface nas condições em que o experimento foi realizado. Para um melhor diagnostico visual das folhas o ideal seria que o experimento continuasse por mais algumas semanas.

\section{Referências}

ABCSEM - Associação Brasileira do Comércio de Sementes e Mudas - Dados

Socioeconômicos da Cadeia Produtiva de Hortaliças no Brasil. Relatório elaborado pelos integrantes da Câmara Setorial de Hortaliças, Cebola e Alho, 201

BORGES, A. L. Avaliação do estado nutricional da bananeira - Diagnose visual. Comunicado Técnico, Cruz das Almas - BA, p. 1-7, 2006.

COSTA, C. P.; SALA, F. C. A evolução da alfacicultura brasileira. Horticultura Brasileira, Brasília-DF, v. 23, n. 1, 2005.

FAQUIN, V. Diagnose do estado nutricional das plantas. Lavras-Mg: UFLA/FAEPE. 77 p.: il. - Curso de Pós-Graduação "Lato Sensu" (Especialização) a Distância: Fertilidade do Solo e Nutrição de Plantas no Agronegócio. 2002.

HOAGLAND, D. R.; ARNON, D. I. The water culture method for growing plants without soil. Calif. Agr. Exp. STA. Cir, p. 347, 1950. 


\section{Omissão de nutrientes na cultura da alface (Lactuca sativa)}

IBGE. Levantamento Sistemático da Produção Agrícola, Rio de Janeiro-RJ, 2017.

KIRKBY, E. A.; ROMHELD, V. Micronutrientes na fisiologia de plantas: funções, absorção e mobilidade. Encarte técnico. No. 118. 2007

MAKISHIMA, N.; MELO, W. F. O rei das hortaliças. Revista Cultivar HF. Pelotas, v. 5, n.29, p. 28-32, 2005.

MALAVOLTA, E. Manual de Nutrição Mineral de Plantas. 1 ed. São Paulo: Editora Agronômica Ceres, p. 638, 2006.

MALAVOLTA, E.; VITTI, G.C.; OLIVEIRA, S.A. Avaliação do estado nutricional das plantas: princípios e aplicações. Piracicaba: Associação Brasileira para Pesquisa da Potassa e do Fosfato, p. 319, 1997.

MARSHNER, P. Mineral nutrition of higher plants. Ed.3. San Diego, USA: Academic press Elsevier. 2012

MENGEL, K.; KIRKBY, E. A. Principles of plant nutrition. Bern, International Potash Institute. p. 687, 1987.

PETRAZZINI L.L.; SOUZA R.J.; OLIVEIRA D.F.; MORALES R.G.F. Sintomas visuais de deficiências nutricionais em afcace americana. Horticultura Brasileira, 2011.

PRADO, R. de M. Nutrição de Plantas. 1 ed. São Paulo: Editora UNESP, p. 407, 2008. 


\section{Omissão de nutrientes na cultura da alface (Lactuca sativa)}

RIJK ZWAAN. Sementes peletizadas de alface crespa verde. Disponível em Https://loja. rijkzwaan.com.br/sementes/alface/jonction-rz/. Acesso em; 9 de jun. 2020

SAS System. SAS Institute Inc. SAS OnlineDoc® 9.1.2. Cary, NC: SAS Institute, 2004.

SOUZA, F. B. M.; PIO, R.; COELHO, V. A. T.; RODAS, C. L.; SILVA, I. P. Sintomas visuais de deficiência de macronutrientes, boro e ferro e composição mineral de amoreira preta. Pesquisa Agropecuária Tropical, 2015.

SOUZA, L. de S.; RESENDE, P. Manual de horticultura orgânica. 2. ed. Viçosa: Aprenda Fácil, p. 743, 2006.

TAIZ, L.; ZEIGER, E. Fisiología vegetal. 4a edição. Artmed, Porto Alegre-RS. p. 848, 2009

TISCHER, J. C; SIQUEIRA NETO, M. Avaliação da deficiência de macronutrientes em alface crespa. Ensaios e Ciência, Campo Grande-MS, v. 16, n. 2, p. 2-16, 2012.

UNIFERTIL UNIVERSAL DE FERTILIZANTES. Do que as plantas precisam? Nutrientes, Canoas-MG, n. 002, p. 1-10, 2012.

Submetido em 28 de outubro de 2020

Aceito em 20 de novembro de 2020

Publicado em 18 de dezembro de 2020 